This is the author's final, peer-reviewed manuscript as accepted for publication. The publisher-formatted version may be available through the publisher's web site or your institution's library.

\title{
Effect of flaxseed flour incorporation on the physical properties and consumer acceptability of cereal bars
}

H. Khouryieh and F. Aramouni

\section{How to cite this manuscript}

If you make reference to this version of the manuscript, use the following information:

Khouryieh, H., \& Aramouni, F. (2013). Effect of flaxseed flour incorporation on the physical properties and consumer acceptability of cereal bars. Retrieved from http://krex.ksu.edu

\section{Published Version Information}

Citation: Khouryieh, H., \& Aramouni, F. (2013). Effect of flaxseed flour incorporation on the physical properties and consumer acceptability of cereal bars. Food Science and Technology International, 19(6), 549-556.

Copyright: @ The Author(s)

Digital Object Identifier (DOI):10.1177/1082013212462231

Publisher's Link: http://fst.sagepub.com/content/19/6/549

This item was retrieved from the K-State Research Exchange (K-REx), the institutional repository of Kansas State University. K-REx is available at http://krex.ksu.edu 
Effect of flaxseed flour incorporation on the physical properties and consumer acceptability of cereal bars

\author{
H. Khouryieh ${ }^{\mathrm{a}}$ and F. Aramouni ${ }^{\mathrm{b}}$ \\ ${ }^{a}$ Food Processing and Technology, Western Kentucky University, Owensboro, KY, USA \\ ${ }^{\mathrm{b}}$ Food Science Institute, Kansas State University, Manhattan, KS, USA
}

${ }^{a}$ Corresponding author. TEL: 270-852-6407; FAX: 270-684-0101; EMAIL:

hanna.khouryieh@wku.edu 


\begin{abstract}
Extensive research has revealed numerous nutritional and health benefits of flaxseed due primarily to its nutrients content. The objective of this study was to evaluate the effect of flaxseed flour addition on the physical and sensory characteristics of cereal bars. Four formulations of the flaxseed cereal bars were prepared by partially replacing oats with flaxseed flour added at levels of 0 (control), 6, 12, and 18\%. There were no significant differences $(P>0.05)$ in water activity, moisture, and firmness values between the flaxseed bars and control. Flaxseed addition significantly $(P<0.05)$ decreased lightness and increased redness of the bars. There were no significant differences $(P>0.05)$ between the $12 \%$ flax cereal bars and the control with respect to sensory attributes and overall acceptability. The overall acceptability for both $12 \%$ flax bars and the control was in between "like moderately" and "like slightly" on the 9-point hedonic scale. The overall acceptability was most highly correlated with flavor acceptability for both control $(\mathrm{r}=$ $0.80)$ and $12 \%$ flax $(r=0.82)$ cereal bars. Flaxseed bars provided $12 \%$ dietary fiber of the daily recommended value. These results indicated that flaxseed flour incorporation up to $12 \%$ substantially enhanced the nutritional qualities of the cereal bars without affecting their sensory and quality properties.
\end{abstract}

Key words: Physical properties, consumer acceptability, nutritional composition, flaxseed, cereal bars 


\section{INTRODUCTION}

Consumers are increasingly interested in functional foods due to the growing awareness of the link between diet and health. Flaxseed (Linum usitatissimum) is an ancient crop that has been gaining recognition as a functional food source (Oomah, 2001;

Hall, 2002; Hall, 2006; Katare et al., 2012). The renewed interest in flaxseed as a functional food source is due to its unique nutrient profile and potential to affect the risk and course of cardiovascular disease and certain types of cancers (Adlercreutz et al., 1992; Bougnoux and Chajes, 2003; Saarinen et al., 2003). Flaxseed is a rich source of $\alpha-$ linolenic acid (ALA), lignans and dietary fiber (Daun et al., 2003; Hall, 2006; Zhang et al., 2011). These nutrients make flaxseed an appealing functional food ingredient (Fitzapatrick, 2007).

Flaxseed incorporation in food products has been the subject of many studies. Ahmed (1999) evaluated the effect of flaxseed meal on the physicochemical properties of an extruded corn snack and reported that with increasing flaxseed meal content, bulk density and breaking strength increased while the expansion ratio decreased. Spaghetti containing flaxseed meal was weaker both before and after cooking compared with spaghetti made with 100\% semolina (Manthey et al., 2000). Shearer and Davis (2005) studied the physicochemical properties of whole-wheat muffins and batter prepared with $0-5 \%$ flaxseed meal and observed changes in batter viscosity, muffin color and texture. The effect of flaxseed $(7.3 \%, 11.6 \%$, and $15.5 \%)$ on the sensory properties of muffins was evaluated and majority of consumers rated control muffin higher than the $11.6 \%$ flaxseed muffin for all sensory attributes and overall acceptability (Ramcharitar et al., 2005). Khouryieh and Aramouni (2012) evaluated the physical and sensory properties of 
flaxseed cookies and indicated that cookies containing flaxseed flour had firmer texture, darker color and lower water activity than the control. Chen et al. (1994) studied the oxidative stability of whole and ground flaxseed, either alone or as an ingredient in a muffin mix. The ALA content decreased from 55.1 to $51.3 \%$ in ground flaxseeds and to $51.7 \%$ in lipid extracts. Whole or ground flaxseed or lipid extracts showed long term stability at room temperature for $280 \mathrm{~d}$. Chen et al. (1994) concluded that under typical baking conditions, there was minimal loss of ALA from flaxseed. Malcolmson et al. (2000) examined the storage stability of milled flaxseed at ambient temperatures for $128 \mathrm{~d}$ and concluded that no significant increase in peroxide values or conjugated double bonds was found during the $128 \mathrm{~d}$-storage period; a trained sensory panel could not detect any differences in the odor properties of fresh or stored milled samples. In a different study conducted by Przybylski and Daun (2001) it was reported that ALA content in milled flaxseed stored at ambient temperatures for up to $20 \mathrm{~m}$ was relatively unchanged and demonstrated resistance to oxidative deterioration. These studies suggest that flaxseed nutrients, lignans and ALA, are stable under normal processing and storage conditions, and flaxseed ingredient creates acceptable food products.

Cereal bars are commonly referred to as snack bars. Cereal bars are often made of a base of processed cereal grains and may contain different ingredients such as nuts, seeds, fruit, raisins, and chocolate. Cereal bars have been used for multiple purposes such as breakfast, snacks, energy, meal replacement, and weight control. Cereal bars are considered healthy foods because they are generally rich in fiber and low in fat (Carvalho et al., 2011). An enriched cereal bar product containing a significant amount of flaxseed and having acceptable sensory characteristics would provide an excellent source for 
consumers to increase consumption of fiber and $\omega-3$ fatty acids. There have been no published studies on the effect of flaxseed flour on the quality properties of cereal bars. The optimal level of flaxseed flour to be incorporated into products without affecting the physical and sensory properties of foods is not clear. The objective of this study was to evaluate the effect of flaxseed flour on the physical characteristics and consumer acceptability of the cereal bars.

\section{MATERIALS AND METHODS}

\section{Materials}

Golden flaxseed flour was purchased from Pizzey's Milling (Gurnee, IL, USA). The nutritional composition of the flaxseed flour is given in Table 1. On arrival, the flaxseed flour was stored in Ziploc plastic bags and kept at $5^{\circ} \mathrm{C}$ in a refrigerator until used. SUPRO ${ }^{\circledR} 313$ isolated soy protein (91\% protein, and $4.5 \%$ moisture) was donated by Solae Company (Saint Louis, MO, USA). KRYSTAR 300 Crystalline fructose was donated by Tate and Lyle (Decatur, IL, USA). Rolled oats, all purpose flour, honey, canola oil, salt, and cinnamon were purchased from local stores.

\section{Cereal bar preparation}

The cereal bar formula was made from $31.3 \%$ rolled oats, $12.5 \%$ all purpose flour, $9.4 \%$ soy protein isolate, $18.8 \%$ crystalline fructose, $12.5 \%$ honey, $2.5 \%$ canola oil, $0.6 \%$ cinnamon, $0.6 \%$ salt and $11.9 \%$ water. Preliminary work was conducted to determine an appropriate flaxseed levels in the formulations. The flaxseed cereal bars were prepared by partially replacing oats with flaxseed flour added at levels of 0 (control), 6, 12, and 18\% (total weight basis). The cereal bar formula varied only in the amount of rolled oats and flaxseed flour. Dry ingredients (rolled oats, flaxseed flour, all 
purpose flour, isolated soy protein, salt, and cinnamon) were mixed using a KitchenAid mixer (St. Joseph, MI, USA) for 2 min at speed 2 to give a uniform mixture. Liquid ingredients (honey and canola oil) were added and mixed for 2 min. Water was incorporated slowly and the entire dough was mixed at speed 2 for 2 min. After mixing, the dough was poured into greased aluminum pans. The dough was compressed with a spatula into metal pans to form a uniform mass. The bars were baked in a conventional oven at $148.9^{\circ} \mathrm{C}$ for $22 \mathrm{~min}$. The pans were cooled to room temperature and the dough was cut into uniform bars $(8 \times 3 \times 2 \mathrm{~cm})$. The bars were stored into Ziploc bags at room temperature and evaluated the next day after baking.

\section{Physical measurements of cereal bars}

Moisture content. Moisture content of the cereal bars was determined according to the AACC method 44-19 (AACC, 2000), using isotemp premium oven 700 series (Fisher Scientific Inc, Dubuque, Iowa). Two grams of crushed cereal bars were placed in weighed aluminum dishes and dried in a hot air oven at $130{ }^{\circ} \mathrm{C}$ for $2 \mathrm{~h}$.

Water activity. The water activity was measured using an Aqua Lab water activity meter series 3TE (Decagon Devices Inc., Pullman, WA). Bar samples were crushed into small pieces and loosely placed into the plastic sample cups until the cups were approximately half full. The cups with the bar samples were then placed into the measuring chamber one at a time.

Texture. The TA.XTPlus Texture Analyzer (Stable Micro System, Scarsdale, NY, USA) with 5-kg load cell was used to measure the hardness of the bars. Bar hardness was measured using a three point bending test. The hardness of the bars was indicated by the maximum peak force required to break the bars. A 5.0-mm stainless steel punch probe 
was used. On the basis of preliminary trials, texture parameters were set to measure compression force at return to start cycle, a pretest speed, test speed, and post-test speed of $10 \mathrm{~mm} / \mathrm{s}, 2 \mathrm{~mm} / \mathrm{s}$ and $10 \mathrm{~mm} / \mathrm{s}$, respectively, and distance of $5 \mathrm{~mm}$. The force-time plots were analyzed to determine the maximum force required to break the bars. A minimum of 9 measurements for each bar were analyzed.

Color analysis. The color of the bars was measured with Miniscan ${ }^{\mathrm{TM}} \mathrm{MS} / \mathrm{S}$ Spectrocolorimeter (Hunter Associates Laboratory Inc., Reston, VA, U.S.A.) at ambient temperature. The colorimeter was calibrated by using white and black standards. The color values $\mathrm{L}^{*}, \mathrm{a}^{*}$, and $\mathrm{b}^{*}$ were measured with a $\mathrm{C}$ illuminant and a $10^{\circ}$ standard observer. The dimension $\mathrm{L}^{*}$ means lightness, with 100 for white and 0 for black, while the $a^{*}$ and $b^{*}$ values range from 60 (red and yellow respectively) to -60 (green and blue respectively). The color measurement was determined on 3 different locations on the same bar.

\section{Sensory evaluation}

Focus group. A focus group session consisting of 6 people was conducted. The main objective of the focus group was to gain an early assessment from panelists on acceptability of cereal bars with 3 levels of ground flaxseed (6.0, 12.0 and 18.0\%) prior to performing a consumer acceptance test. The focus group consisted of four females and two males aged 24-32 years. Participants were selected based on their consumption of cereal bars and willingness to participate. The focus group session was held using a roundtable discussion. The session lasted for $2 \mathrm{~h}$ with a $10 \mathrm{~min}$ break in the middle. Each participant was provided with 3 cereal bars on 3 coded plates. Water was supplied to cleanse palate between samples. The session began with a short introduction, in which 
the participants were told that they were going to taste cereal bars formulated with flaxseed flour. The participants were first allowed to discuss the cereal bars freely, and then the moderator asked questions regarding appearance, color, flavor, texture, and overall acceptability of each bar. The participants were asked to list the positive and negative characteristics of the cereal bars (Resurrection, 1998).

Consumer acceptability. The consumer acceptability study was carried out on a laboratory scale. Laboratory acceptance testing is the most frequently used among the various types of sensory acceptance tests (Stone and Sidel, 2004). Prior to tasting, panelists signed informed consent form and were asked a series of questions about demographic information (gender, age, and education), frequency of consumption of cereal bars, and food allergies. Individuals were excluded if they reported allergies to any food product. Based on the focus group assessment, the $12 \%$ flax bars were compared to the control to evaluate the product's consumer acceptance. A total of 105 untrained panelists participated in the consumer acceptability study. Each panelist evaluated two samples of the bars in one session. Bars were cut in halves ( 30 g/sample) and offered monadically to panelists on odorless plastic plates coded by 3-digit random numbers at room temperature. Water and unsalted crackers were provided to panelists to cleanse their palates between samples. A 9-point hedonic scale $(9=$ like extremely; $5=$ neither like nor dislike; $1=$ dislike extremely) is used to determine degree of liking for products (Peryam and Girardot 1952).

\section{Nutritional analysis}

The nutritional composition of the cereal bars (carbohydrates, fats, protein, fiber, calories, vitamins and minerals) was determined using Genesis R\&D software version 7.1 
(ESHA Research, Salem, OR, USA). All ingredients for every bar were entered into the Genesis software and the moisture content adjusted to reflect the values obtained by the oven method. The nutritional analysis was used to determine allowable claims for the flax cereal bars.

\section{Statistical Analysis}

A completely randomized design with three replications with three subsamples of all experiments was conducted. Statistical analysis was performed using the SAS software version 9.0. (2002-2003). An Analysis of Variance (ANOVA) and Fishers' Least Significant Difference (LSD) comparison was performed on all data to determine the effect of flaxseed flour on the physical and sensory properties of cereal bars. Significant differences among formulations were determined at the significance level of $P<0.05$. A correlation analysis between sensory attributes and overall acceptability was performed using SAS Proc Corr.

\section{RESULTS AND DISCUSSION}

\section{Physical properties of cereal bars}

There were no significant differences $(P>0.05)$ in water activity $(0.69-0.70)$ and moisture content (20.7-20.9\%) between the cereal bars formulated with flaxseed flour and the control, as shown in Table 2. The addition of flaxseed flour up to $18 \%$ did not have any significant effect on the water activity and moisture content of the cereal bars. The water activity concept is widely used to assess the microbial growth, lipid oxidation, non-enzymatic and enzymatic activities, and the texture of finished foods (Rahman and Labuza, 1999). Most food products have a water activity in the range of 0.2 for very dry 
foods to 0.99 for moist fresh foods. Molds and yeasts usually start to grow at a water activity between 0.7 and 0.8 , while the bacterial growth starts to take place at water activity of 0.8 .

The effect of flaxseed flour on the hardness of the snack bars is presented in Table 2. The maximum force required to break the bars was slightly increased as the level of flaxseed flour increased in cereal bars. However, the amount of flaxseed flour used to replace the oats in the cereal bars did not significantly $(P>0.05)$ affect the hardness of the bars. Since the cereal bar formula varied only in the amount of rolled oats and flaxseed flour, the increase in the bar hardness can be attributed to the differences in the composition of the flaxseed flour and oats. Khouryieh and Aramouni (2012) reported that cookie hardness increased as the level of flaxseed flour increased in cookies, and the increase in the cookie hardness was attributed to the high protein content of flaxseed flour. Shearer and Davis (2005) observed a firmer texture for muffins containing up to $5 \%$ flaxseed than the control muffins as shown by the maximum force required to compress the muffins.

Color is one of the most important quality factors affecting consumers' perception and acceptance of food products (Schwartz et al, 2007). Significant differences $(P<$ $0.05)$ were found between the $L^{*}, a^{*}$ and $b^{*}$ values of the four cereal bars (Table 2 ). The cereal bars with flaxseed flour were significantly $(P<0.05)$ darker than the control bars as indicated by lower $\mathrm{L}^{*}$ values. The $6 \%$ and $12 \%$ flax bars had significantly $(P<0.05)$ higher $\mathrm{a}^{*}$ (redness) values than the control, while the $18 \%$ flax bars were not higher $(P>$ 0.05). The $18 \%$ flax bars had a significantly lower $b^{*}$ (yellowness) values than the other treatments. The changes in color values observed for flaxseed bars can be related to the 
Maillard browning reactions possibility between flaxseed protein and other ingredients such as honey. These results are consistent with Khouryieh and Aramouni (2012), who concluded that cookies with increased flaxseed flour levels were significantly darker and redder than the control as indicated by lower $\mathrm{L}^{*}$ and higher $\mathrm{a}^{*}$ values. The results are also in agreement with Koca and Anil (2007), who reported that crumb "L" values decreased and "a" values increased with increasing flaxseed flour levels in bread formulations. Ahmed (1999) reported that flaxseed significantly $(P<0.05)$ reduced brightness and increased redness in corn-flax extruded snack. Similar trends were also shown in flaxseed containing baked goods, as reported by Shearer and Davis (2005) and Alpaslan and Hayta (2006).

\section{Sensory evaluation}

The early assessment for the cereal bar formulations conducted by the focus group revealed that the $12 \%$ flaxseed bars had the highest ratings for all sensory attributes. The majority of the participants agreed that the content of flaxseed in $12 \%$ flax bars was just about right. The focus group participants described the $12 \%$ flax bars as "having a pleasant taste," "nice nutty flavor," "good texture," "not dark in color," and "good appearance." The $6 \%$ flaxseed bars were similar to the $12 \%$ flaxseed bars in terms of color and texture, but the flavor was not as good as the $12 \%$ flaxseed bars. The $18 \%$ flaxseed bars had the lowest ratings. The $18 \%$ flax bars were described as "having an unpleasant taste," "too dry," "dark in color," and "unattractive appearance." Therefore, the $12 \%$ flaxseed bars were selected to conduct the consumer acceptability study.

A total of 105 panelists participated in the consumer acceptability study including 69 females and 36 males, accounting for 65.7 and 34.3\% respectively, between 18 and 65 
years of age (74\% ages $18-30,17 \%$ ages $31-55,9 \%$ ages 56-65). With regards to education $12 \%$ finished high school, $38 \%$ had some college or technical school, $29 \%$ were college grad and $21 \%$ were post grads. Mean acceptance scores of sensory attributes (appearance, color, flavor, texture, and overall acceptability) are shown in Figure 1. The $12 \%$ flaxseed cereal bars were compared with the control ( $0 \%$ flaxseed flour). There were no significant differences $(P>0.05)$ between the $12 \%$ flaxseed bars and the control with respect to appearance, color, flavor, texture, and overall acceptability. The overall acceptability for both flaxseed cereal bars was in between "like moderately" and "like slightly" on 9-point hedonic scale. The mean value of overall acceptability for the $12 \%$ flaxseed bars was 6.2 , comparing to 6.3 for the control. These results may indicate that subjects were unable to distinguish the $12 \%$ flaxseed bars from the control bars. These results are consistent with Khouryieh and Aramouni (2012), who reported that 6 and 12\% flaxseed cookies were the most preferred among consumers, while the flaxseed flour substituted at $18 \%$ was shown to have a negative effect on all the sensory attributes. Consumer acceptability of muffins with flaxseed was investigated by Ramcharitar et al. (2005) who reported that the majority of consumers rated $(P<0.001)$ the control muffin (0\% flaxseed) higher than the $11.6 \%$ flaxseed muffin for all sensory attributes and overall acceptability. The high acceptance of our $12 \%$ flaxseed formulation by consumers may be related to the desirable flavor of cinnamon. Many consumers who participated in the acceptance test commented that the cinnamon aroma of the cereal bars was very strong and appealing. Yeu et al. (2008) reported that addition of cinnamon flavor improved overall, aroma, and taste acceptance scores in an extruded soy-based high-protein breakfast cereal by masking the undesirable soy aromas of the samples. 
A correlation between sensory attributes and overall acceptability was conducted to better understand the relationships between sensory attributes of cereal bars and assess the impact of sensory attributes on the overall acceptability (Table 3). The overall acceptability was most highly correlated with flavor acceptability for both control ( $\mathrm{r}=$ $0.80)$ and $12 \%$ flax $(r=0.82)$ cereal bars. For the control cereal bars, color scores followed next and positively correlated $(r=0.74)$ while, for the $12 \%$ flax cereal bars, the sensory texture scores were next to the flavor and positively correlated $(r=0.67)$ with overall acceptability. Overall acceptability was also moderately correlated with sensory scores of appearance for both control $(\mathrm{r}=0.58)$ and $12 \%$ flax $(\mathrm{r}=0.51)$ cereal bars. These results suggest that the flavor attribute was the most critical factor in consumer preferences for overall acceptability. These results are in agreement with Ramcharitar et al. (2005) who reported that flaxseed muffin flavor was most strongly and positively correlated $(p<0.01, \mathrm{r}=0.82)$ with overall acceptability, which highlighted the importance of developing strategies to minimize undesirable flavors arising from the use of flaxseed flour. Khouryieh and Aramouni (2012) reported that the flaxseed cookie flavor was the most highly correlated with the overall acceptability $(r=0.90)$.

\section{Nutritional analysis}

The nutrient contents for the cereal bars formulated with flaxseed flour are shown in Table 4. The official serving size by Food and Drug Administration for cereal bars is 1 bar (40g). Nutritional labels of various commercial bars in the United States have a range of net weights per 1 bar serving size from 40 to $60 \mathrm{~g}$, depending on the type of bar. The total fat content in the cereal bar formulations increased as the percent of flaxseed flour increased. While the amount of monounsaturated fatty acids remained constant, the 
amount of polyunsaturated fatty acids increased substantially in the flaxseed formulations comparing to the control. The amount of the polyunsaturated fatty acids increased by $50 \%$ in the $6 \%$ flaxseed formulation and by $75 \%$ in both the 12 and $18 \%$ flaxseed formulations comparing to the control. This increase is attributed to the high fat content of flaxseed flour. Menteş et al. (2008) reported that oil content and proportion of linolenic acid in fatty acid composition increased as the ratio of flaxseed flour in bread formulation was increased. According to Daun et al. (2003) flaxseed oil content has a range of 38$45 \%$ fat depending on location, cultivar, and environmental conditions, of which $73 \%$ is polyunsaturated fatty acids and $18 \%$ monounsaturated fatty acids. Although the amount of total carbohydrates decreased as the amount of flaxseed flour increased in the cereal bar formulations, the amount of dietary fiber increased by $33 \%$ for both the 12 and $18 \%$ flaxseed formulations. The high increase in fiber content can be related to the differences in composition of flaxseed flour. Flaxseed is a rich source of dietary fiber and accounts for $28 \%$ of its composition (Hall et al., 2006). Dietary fiber has been widely viewed as a component essential in lowering the risk of colon cancer (Hall et al., 2006). The nutrient content indicated that the $12 \%$ and $18 \%$ flax bar formulations would be considered a "good source of fiber," providing $12 \%$ of the daily reference value. A "good source of

fiber" claim requires fiber content of $10-19 \%$ of the daily reference value (21CFR 101.54).

\section{CONCLUSIONS}

The cereal bars quality was strongly affected by the chemical composition of the flaxseed flour. Flaxseed flour incorporation up to $12 \%$ substantially enhanced the nutritional qualities of the cereal bars without affecting their sensory and quality 
properties. Consumer acceptability results indicated that subjects were unable to distinguish between the $12 \%$ flax cereal bars and the control. The correlation results suggested that the flavor attribute was the most critical factor in consumer preferences for overall acceptability of flaxseed cereal bars. The amounts of the polyunsaturated fat and dietary fiber increased substantially in the flaxseed cereal bars. The nutrient content indicated that the $12 \%$ and $18 \%$ flax bar formulations would be considered a "good source of fiber," providing $12 \%$ of the daily reference value.

\section{REFERENCES}

Oomah D. (2001). Flaxseed as a functional source. Journal of the Science of Food Agriculture 81(9): 889-904.

Hall C III. (2002). Flaxseed as a functional food. In: Proceedings of the $59^{\text {th }}$ Flax Institute of the United States, 21-23 March, 2002 Fargo, ND: pp. 21-24.

Hall C III, Tulbek MC and Xu Y. (2006). Flaxseed. Advances in Food and Nutrition Research 51: 1-97.

Katare C, Saxena S, Agrawal S, Prasad GBKS and Bisen PS. (2012). Flax Seed: A Potential Medicinal Food. Journal of Nutrition and Food Sciences 2(1): 1-8.

Adlercreutz H, Mousavi Y, Clark I, Hockerstedt K, Hamalainen F, et al. (1992). Dietary phytoestrogens and cancer in vitro and in vivo studies. Journal of Steroid Biochemistry and Molecular Biology 41: 331-337.

Bougnoux P and Chajes V. (2003). $\alpha$ - linolenic acid and heart disease. In: Cunnane SC and Thompson LU (eds), Flaxseed in Human Nutrition. Champaign, IL: AOCS Press, pp. 232-241.

Saarinen NM, Makela S and Satti R. (2003). Mechanisms of anticancer effects of lignans with a special emphasis on breast cancer. In: Cunnane SC and Thompson LU (eds), Flaxseed in Human Nutrition. Champaign, IL: AOCS Press, pp. 223-228.

Daun JK, Barthet JV, Chornick TL and Duguid S. (2003). Structure, composition, and variety development of flaxseed. In: Cunnane SC and Thompson LU (eds), Flaxseed in 
Human Nutrition. Champaign, IL: AOCS Press, pp. 1- 40.

Zhang Z, Wang L, Li D, Li S and Özkan N. (2011). Characteristics of Flaxseed Oil from Two Different Flax Plants. International Journal of Food Properties 14(6): 1286-1296.

Fitzapatrick K. (2007). Innovation in western Canadian functional food ingredients. Cereal Foods World 52(5): 289-290.

Ahmed ZS. (1999). Physico-chemical, structural and sensory quality of corn-based flax snack. Nahrung/Food 43(4): 253-258.

Manthey FA, Lee RE and Hall CA. (2002). Processing and cooking effects on lipid content and stability of a-linolenic acid in spaghetti containing ground flaxseed. Journal of Agricultural and Food Chemistry 50(6): 1668-1671.

Shearer AEH and Davis CGA. (2005). Physicochemical properties of freshly baked and stored whole-wheat muffins with and without flaxseed meal. Journal of Food Quality 28(2): 137-153.

Ramcharitar A, Badrie N, Mattfeldt-Beman M, Matsuo H and Ridley C. (2005). Consumer acceptability of muffins with flaxseed (Linum usitatissimum). Journal of Food Science 70(7): S504-S507.

Khouryieh H and Aramouni F. (2012). Physical and sensory characteristics of cookies prepared with flaxseed flour. Journal of the Science of Food and Agriculture 92(11): 2366-2372.

Chen ZY, Ratnayake WMN and Cunnane SC. (1994). Oxidative stability of flaxseed lipids during baking. Journal of the American Oil Chemists' Society 71(6): 629-632.

Malcolmson LJ, Przybylski $a$ R and Daun JK. (2000). Storage stability of milled flaxseed. Journal of the American Oil Chemists' Society 77(3): 235-238.

Przybylski R and Daun JK. (2001). Additional data on the storage stability of milled flaxseed. Journal of the American Oil Chemists' Society 78(1): 105-106.

Carvalho MG, Costa JMC, Rodrigues MCP, Sousa PHM and Clemente E. (2011). Formulation and sensory acceptance of cereal-bars made with almonds of chichá, sapucaia and gurguéia nuts. The Open Food Science Journal 5: 26-30.

AACC. (2000). Approved Methods of the AACC, $10^{\text {th }}$ edn. St Paul: American Association of Cereal Chemists.

Resurrection AVA. (1998). Consumer Sensory Testing for Product Development. Gaithersburg, MD: Aspen Publishers, pp. 93-112. 
Stone H and Sidel J. (2004). Sensory Evaluation Practices, $3^{\text {rd }}$ edn. California: Academic Press Inc.

Peryam DR and Girardot NF. (1952). Advanced taste test method. Food Engineering 24:58-61.

SAS (2002-2003) SAS user's guide: Statistics. Software Release 9.1, SAS Institute Inc., Cary, NC, USA.

Rahman MS and Labuza TP. (1999). Water activity and food preservation. In: Rahman MS (ed) Handbook of Food Preservation. New York: Marcel Dekker, pp. 339-382.

Schwartz SJ, von Elbe JH and Giusti MM. (2008). Colorants. In: Damodaran S, Parkin KL and Fennema OR (eds), Fennema's Food Chemistry. Boca Raton, FL: CRC Press, pp. 571-638.

Koca AF and Anil M. (2007). Effect of flaxseed and wheat flour blends on dough rheology and bread quality. Journal of the Science of Food and Agriculture 87(6): 1172-1175.

Alpaslan M and Hayta M. (2006). The effects of flaxseed, soy and corn flours on the textural and sensory properties of a bakery product. Journal of Food Quality 29(6): 617627.

Yeu K, Lee Y and Lee SY. (2008). Consumer acceptance of an extruded soy-based highprotein breakfast cereal. Journal of Food Science 73(1): S20-S25.

Menteş Ö, Bakkalbaşşi E and Ercan R. (2008). Effect of the use of ground flaxseed on quality and chemical composition of bread. Food Science and Technology

International 14(4): 299-306.

Code of Federal Regulations. (2011). 21CFR101.54. Available at:

http://www.accessdata.fda.gov/scripts/cdrh/cfdocs/cfcfr/CFRSearch.cfm?fr=101.54 (accessed 10 April 2012). 
Table 1. Proximate composition of flaxseed flour

\begin{tabular}{lc}
\hline Component & Amount per 100g \\
\hline Energy (Kcal) & 470 \\
Total Fat (g) & 37.0 \\
Saturated (g) & 3.4 \\
Polyunsaturated fatty acids (g) & 27.0 \\
$\quad$ (Omega 3) $\alpha$-Linolenic Acid (g) & 20.0 \\
$\quad$ Omega 6) Linoleic Acid (g) & 6.0 \\
Monounsaturated fatty acids (g) & 6.6 \\
Trans Fatty Acids (g) & $<0.1$ \\
Cholesterol (mg) & 0 \\
Total Carbohydrates (g) & 29.0 \\
Sugars (g) & 2.0 \\
Dietary Fiber (g) $\quad 27.0$ \\
$\quad$ Soluble (g) & 9.0 \\
$\quad$ Insoluble (g) & 18.0 \\
Protein (g) & 20.0 \\
Moisture (g) & 8.0 \\
Ash (g) & 3.6 \\
\hline
\end{tabular}


Table 2. Effects of flaxseed flour on the water activity, moisture content, texture and color of the flaxseed cereal bars ${ }^{1}$

\begin{tabular}{|c|c|c|c|c|c|c|}
\hline \multirow{2}{*}{$\begin{array}{c}\text { Flaxseed Level } \\
(\%)\end{array}$} & \multirow[t]{2}{*}{ Water activity } & \multirow{2}{*}{$\begin{array}{c}\text { Moisture } \\
\text { content }(\%)\end{array}$} & \multirow[t]{2}{*}{ Hardness (g) } & \multicolumn{3}{|c|}{ Color $^{2}$} \\
\hline & & & & $\mathbf{L}^{*}$ & $\mathbf{a}^{*}$ & $\mathbf{b}^{*}$ \\
\hline 0 & $0.70^{\mathrm{a}} \pm 0.01$ & $20.7^{\mathrm{a}} \pm 1.0$ & $1895^{\mathrm{a}} \pm 331$ & $51.60^{\mathrm{c}} \pm 1.73$ & $14.08^{\mathrm{a}} \pm 0.75$ & $30.18^{a} \pm 0.69$ \\
\hline 6 & $0.69^{\mathrm{a}} \pm 0.01$ & $20.7^{\mathrm{a}} \pm 1.4$ & $1916^{a} \pm 254$ & $48.63^{\mathrm{ab}} \pm 2.46$ & $15.29^{c} \pm 1.04$ & $30.27^{\mathrm{a}} \pm 1.58$ \\
\hline 12 & $0.69^{a} \pm 0.01$ & $20.9^{\mathrm{a}} \pm 1.0$ & $1912^{a} \pm 291$ & $49.68^{b} \pm 1.71$ & $14.92^{b} \pm 0.89$ & $30.79^{a} \pm 0.71$ \\
\hline 18 & $0.70^{\mathrm{a}} \pm 0.01$ & $20.7^{\mathrm{a}} \pm 2.8$ & $1940^{a} \pm 255$ & $47.55^{\mathrm{a}} \pm 1.14$ & $14.47^{\mathrm{ab}} \pm 0.84$ & $28.63^{\mathrm{b}} \pm 1.47$ \\
\hline $\mathrm{LSD}^{3}$ & 0.01 & 1.2 & 201.3 & 1.29 & 0.63 & 0.84 \\
\hline
\end{tabular}

${ }^{a b c}$ Means with different superscripts in columns indicate significant difference $(P<0.05)$.

1 Values are expressed as means \pm standard deviations $(n=3)$

$2 \mathrm{~L}^{*}$ designates the lightness of the sample, $100=$ white, $0=$ black; $\mathrm{a}^{*}$ (ranges from 60 to -60 ) indicates redness when positive, greenness when negative; $b^{*}$ (ranges from 60 to -60) indicates yellowness when positive, blueness when negative.

LSD represents least significant difference. 
Table 3. Correlation coefficients ${ }^{1}$ (r-values) between overall acceptability and sensory attributes of control and flaxseed supplemented flour cereal bars

\begin{tabular}{lcc} 
sensory attributes of control and flaxseed supplemented flour cereal bars \\
\cline { 2 - 3 } Sensory attributes & \multicolumn{2}{c}{ Overall acceptability } \\
\hline Appearance & $0.58\left(r^{2}=0.34\right)$ & $\mathbf{1 2 \%}$ Flaxseed \\
Color & $0.51\left(r^{2}=0.26\right)$ \\
Flavor & $0.80\left(r^{2}=0.55\right)$ & $0.56\left(r^{2}=0.31\right)$ \\
Texture & $0.71\left(r^{2}=0.50\right)$ & $0.82\left(r^{2}=0.67\right)$ \\
& & $0.67\left(r^{2}=0.45\right)$
\end{tabular}

${ }^{1}$ Significant at the 0.0001 level 
Table 4. Nutritional analysis ${ }^{1}$ for control cereal bars and cereal bars formulated with various levels of flaxseed flour

Control $\quad 6 \%$ Flaxseed $\quad 12 \%$ Flaxseed

\begin{tabular}{|c|c|c|c|c|c|c|c|}
\hline & $\begin{array}{l}\text { Reference } \\
\text { Value }^{1}\end{array}$ & Amount & $\begin{array}{l}\% \text { Daily } \\
\text { value }\end{array}$ & Amount & $\begin{array}{l}\% \text { Daily } \\
\text { value }\end{array}$ & Amount & $\begin{array}{l}\% \quad \mathrm{Da} \\
\text { value }\end{array}$ \\
\hline Total Calories & 2,000 & 130 & - & 140 & - & 140 & - \\
\hline Calories from fat & - & 20 & - & 20 & - & 30 & - \\
\hline Total fat (g) & 65 & 2 & 3 & 3 & 5 & 3.5 & 5 \\
\hline Saturated fat (g) & 20 & 0 & 0 & 0 & 0 & 0.5 & 2 \\
\hline Trans fat $(\mathrm{g})$ & - & 0 & - & 0 & - & 0 & - \\
\hline Polyunsaturated fat (g) & - & 0.5 & - & 1 & - & 2 & - \\
\hline Monounsaturated fat (g) & - & 1 & - & 1 & - & 1 & - \\
\hline Cholesterol (mg) & 300 & 0 & 0 & 0 & 0 & 0 & 0 \\
\hline Sodium (mg) & 2,400 & 130 & 5 & 130 & 5 & 130 & 5 \\
\hline Total carbohydrate (g) & 300 & 24 & 8 & 22 & 7 & 22 & 7 \\
\hline Dietary fiber (g) & 25 & 2 & 8 & 2 & 8 & 3 & 12 \\
\hline Sugars (g) & - & 11 & - & 11 & - & 11 & - \\
\hline Protein (g) & 50 & 5 & - & 6 & - & 6 & - \\
\hline Vitamin A (IU) & - & - & 0 & - & 0 & - & 0 \\
\hline Vitamin C (mg) & - & - & 0 & - & 0 & - & 0 \\
\hline Calcium (mg) & - & - & 2 & - & 2 & - & 2 \\
\hline Iron (mg) & - & - & 6 & - & 6 & - & 6 \\
\hline
\end{tabular}

${ }^{1}$ Percent daily values are based on a 2000-calorie diet. 


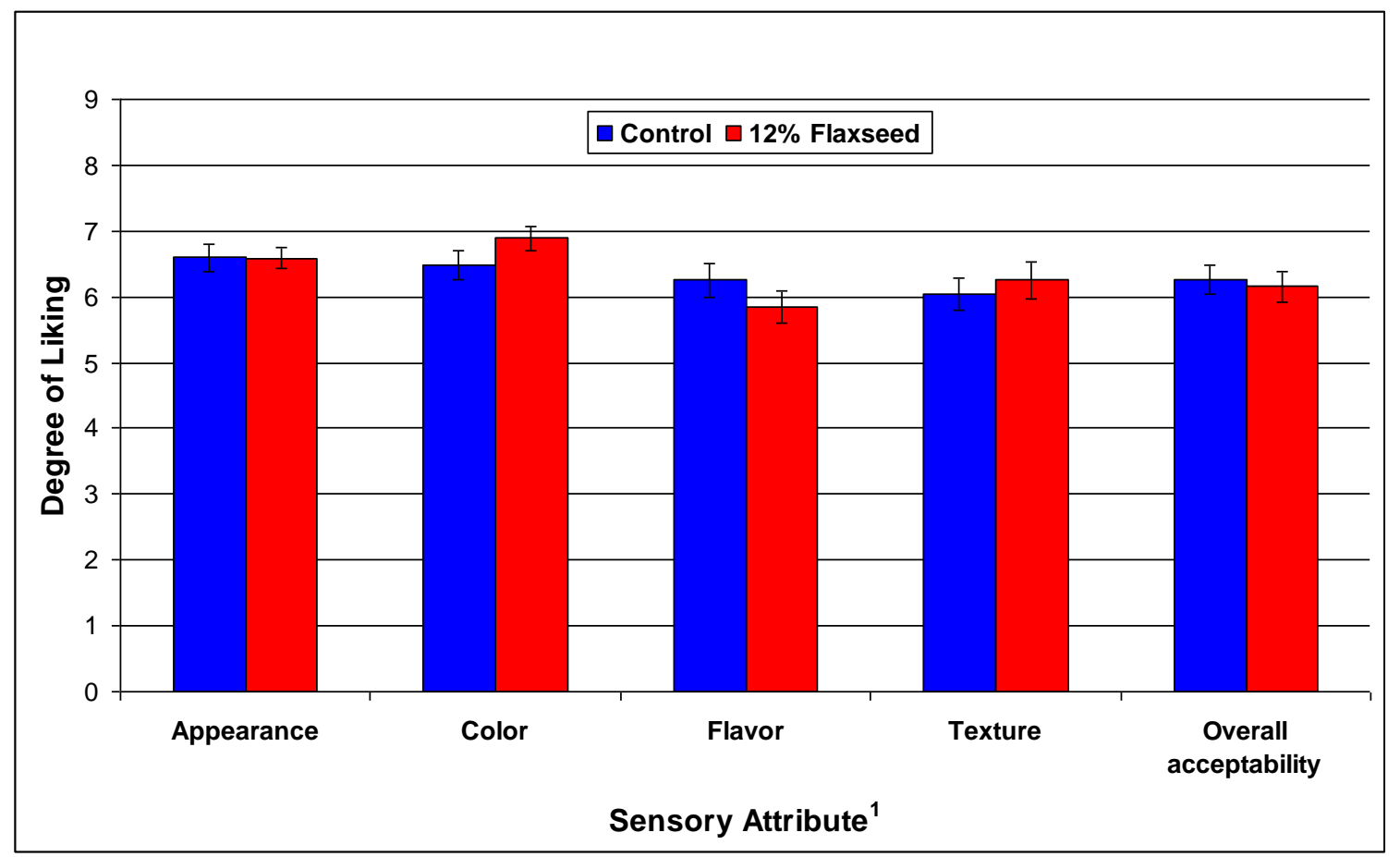

Figure 1. Mean sensory attributes of control and $12 \%$ flaxseed cereal bars.

${ }^{1}$ Sensory attributes as determined by consumer evaluation $(\mathrm{N}=105)$ on a 9-point hedonic Scale: 1- dislike extremely, 5-neither like nor dislike, 9- like extremely. Sensory values are expressed as means of 3 replicates. Error bars represent standard errors. No significant differences $(P>0.05)$. 